\title{
PERMAINAN IPA SEDERHANA BAGI PENGAJAR ANAK JALANAN DAN MARGINAL
}

\author{
Oleh: \\ Endang Susantini', Laily Rosdiana², Ika Kurniasari ${ }^{3}$ \\ 'Jurusan Biologi, FMIPA Unesa \\ 2Jurusan IPA, FMIPA Unesa \\ 3Jurusan Matematika, FMIPA Unesa \\ 1endangsusantini@unesa.ac.id
}

\begin{abstract}
Abstrak
Tujuan kegiatan ini adalah meningkatkan keterampilan pengajar anak jalanan dan marginal dalam membuat media permainan IPA yang sederhana. Pengajar anak jalanan dan marginal yang dimaksud adalah pengajar pada komunitas Save Street Child/SSC Surabaya dan pengajar anak terdampak penutupan lokalisasi Dolly Surabaya yaitu Gerakan Melukis Harapan/GMH. Jumlah pengajar yang terlibat 28 orang yang dibagi dalam 8 kelompok. Metode yang dipilih untuk mencapai tujuan di atas adalah pelatihan yang dilakukan secara bertahap. Tahap pertama, adalah mendemonstrasikan cara membuat media permainan IPA yang sederhana. Tahap kedua, mendemonstrasikan cara menulis aturan permainan dengan kalimat yang mudah diikuti atau operasional. Tahap ketiga, melakukan modeling cara mengajar dengan menggunakan media permainan IPA. Pada setiap langkah diikuti penugasan secara kelompok. Tahap keempat, setiap kelompok pengajar diminta mendemonstrasikan permainan IPA sederhana buatan sendiri. Hasil kegiatan menunjukkan dari 8 kelompok pengajar anak jalanan dan marginal berhasil membuat 7 permainan IPA sederhana dengan baik dan melakukan simulasi permainan buatan sendiri.
\end{abstract}

Kata Kunci: Pengajar Anak Jalanan dan Marginal, Permainan IPA Sederhana, Pelatihan

\section{Abstract}

The purpose of this activity is to improve the skills of teachers for street and marginal children in creating a simple science game media. The teachers' street and marginal children are teachers in the community of Save Street Child/SSC Surabaya and child educators affected by the closing of Surabaya Dolly localization, namely, the Painting of Hope Movement (GMH as written in Bahasa). Number of teachers involved was 28 people divided into 8 groups. The method chosen to achieve the above objectives was a gradual training. The first stage was to demonstrate how to create a simple science game media. The second stage was to demonstrate how to write the game rules with easy-to-follow or operational sentences. The third stage was to model the way of teaching by using the science game media. Each step was followed by group assignments. Fourth stage was that each group of teachers was asked to demonstrate a simple homemade science game. The results showed that from 8 groups of street children and marginal students managed to make 7 simple science games well and do the simulation of homemade games.

Keywords: Teachers' Street and Marginal Children, Simple Science Game, Training

\section{PENDAHULUAN}

Anak jalanan berhak mendapat pengajaran, hal ini sesuai dengan pasal 31 ayat 1 UUD 1945 yang mengamanatkan bahwa setiap warga negara berhak mendapat pengajaran. Melihat isi dari pasal 31 ayat 1 tersebut sangat bertolak belakang dengan kondisi yang dialami anak jalanan. Mereka hampir tidak mendapatkan pengajaran, karena tidak banyak yang mempedulikan nasib dan masa depan mereka. Lembaga sosial yang memberikan uluran tangan bagi komunitas anak jalanan di Surabaya yaitu Save Street Child (SSC) Surabaya dan Gerakan Melukis Harapan (GMH) yang merupakan komunitas mitra dalam kegiatan PKM lbM ini.

Save Street Child (SSC) Surabaya adalah sebuah komunitas pemerhati dan peduli anak 
jalanan dan marginal kota Surabaya. Save Street Child (SSC) Surabaya telah terbentuk sejak tanggal 5 Juni 2011 hingga sampai saat ini memiliki pengurus tetap sebanyak 8 orang. Saat ini, tempat yang digunakan base camp SSC Surabaya adalah JI. Semampir Selatan 2a/45 Surabaya.

Save Street Child (SSC) Surabaya mempunyai visi dan misi dalam mencerdaskan anak jalanan. Visi SSC Surabaya ialah terwujudnya hak-hak anak sesuai dengan harkat dan martabat anak bangsa yang agung dan berbudi luhur. Sedangkan misi SSC Surabaya ialah mewujudkan hak-hak anak Indonesia; mewujudkan rasa keadilan sesuai dengan nilai-nilai kemanusiaan; wadah bagi pemuda pemudi (masyarakat) Surabaya untuk lebih peduli dengan anak jalanan dan marginal; menumbuhkan persamaan hak antara anak jalanan dan marginal dengan seluruh masyarakat Indonesia; turut serta mencerdaskan anak bangsa dengan membimbing ke jalan yang baik dan benar.

Salah satu program SSC Surabaya adalah Pengajar Keren, yang merupakan program mengajar anak-anak jalanan. Kata Keren menurut SSC Surabaya berarti jika kita mau berbagi baik dalam bentuk tenaga, pikiran, materi, atau hal apapun tanpa harus mengharapkan imbalan. Tujuan dasar dibentuk program Pengajar Keren adalah turut mencerdaskan anak bangsa. Ada empat lokasi yang biasa digunakan pengajar dalam melaksanakan kegiatan belajar mengajar yaitu (1) kawasan Stren Kali Jembatan Merah Plaza (JMP) sudah ada sekitar 50 anak didik, (2) kawasan makam Rangkah sudah ada 50 anak didik, (3) kawasan Traffic Light Jl. Dr. Moestopo sudah ada 70 anak didik, (4) kawasan Taman Bungkul ada 20 anak didik. Jumlah pengajar volunteer yang tercatat sekitar 100 orang tetapi yang aktif 25-30 orang yang tersebar di empat kawasan belajar.

Tujuan yang diimpikan oleh komunitas SSC Surabaya tidak didukung oleh sarana dan prasarana yang dimilikinya. Kondisi tempat kegiatan belajar mengajar anak jalanan memprihatinkan. SSC Surabaya tidak mempunyai tempat khusus untuk melakukan kegiatan belajar mengajar seperti halnya sekolah. Tempat pembelajaran yang digunakan merupakan tempat seadanya yang dipinjami oleh masyarakat sekitar. Tempat pembelajaran tanpa meja dan kursi layaknya di sekolah formal. Sarana dan prasarana yang masih ala kadarnya, tanpa media pembelajaran yang dapat mempermudah memahami pembelajaran. Pengajar SSC Surabaya umumnya mahasiswa, pegawai, bahkan kakak pengamen yang berasal dari latar belakang pendidikan berbeda-beda. Pengajar SSC Surabaya merupakan pemuda-pemudi volunteer yang berbekal semangat tinggi untuk mencerdaskan anakanak jalanan. Masalah yang sering diutarakan anak jalanan selama belajar adalah tentang kesulitan memahami pelajaran Matematika dan IPA. Di lain pihak, para pengajar kurang memiliki pengetahuan yang cukup tentang cara mengajar Matematika dan IPA yang baik. Para pengajar mengandalkan suara keras, berteriak-teriak, bahkan sering kali terucap suaranya habis saat mengajar anak jalanan. Para pengajar tidak terpikir untuk menggunakan media permainan Matematika dan IPA yang dapat menarik perhatian anak jalanan, menarik minat belajar anak jalanan karena disajikan dengan cara bermain. Oleh karena itu, Tim pelaksana IbM terpanggil untuk memberikan pelatihan tentang cara membuat media permainan matematika dan IPA kepada para pengajar anak jalanan.

Komunitas sosial lain yang peduli dengan pendidikan anak-anak marginal adalah Gerakan Melukis Harapan (GMH). GMH merupakan gerakan yang mengawal masyarakat terdampak penutupan lokalisasi Dolly agar dapat hidup normal tanpa membuka usaha lokalisasi. Basecamp GMH berada di Jl. Klampis Sacharosa 51 Surabaya. Gerakan Melukis Harapan terbentuk pada 10 September 2014, tiga bulan setelah penutupan lokalisasi oleh Pemkot Surabaya pada 18 Juni 2014. Salah alasan kuat Pemkot Surabaya menutup Dolly adalah ingin menyelamatkan anak-anak Dolly dari dampak negatif lingkungan lokalisasi.

Pasca penutupan lokalisasi Dolly muncul masalah yaitu hilangnya penghasilan warga daerah Putat Jaya Surabaya yang berdampak pada anak-anak yaitu putus sekolah dan psikis terganggu. Anak-anak terdampak penutupan Dolly butuh pendampingan secara berkelanjutan. Komunitas GMH memiliki visi yaitu menciptakan pembaharuan sosial untuk mewujudkan kesejahteraan umum, sesuai dengan cita-cita Bangsa Indonesia dalam pembukaan UUD 1945. Bidang Pendidikan merupakan salah satu program GMH yang memberikan pengajaran bagi anak-anak yang hidup dan tinggal di sekitar daerah eks lokalisasi Dolly-Jarak Surabaya. 
SSC Surabaya memiliki program Pengajar Keren, maka $\mathrm{GMH}$ memiliki program $\mathrm{GMH}$ Mengajar yang bertujuan memotivasi anakanak untuk melanjutkan sekolah, memberikan bantuan agar anak-anak dapat tumbuh dan berkembang lebih baik dari sebelumnya. GMH Mengajar melakukan pendampingan belajar secara akademis kepada anak-anak di kawasan Dolly-Jarak. Jumlah anak didik GMH 30-40 anak dan pengajar volunteer $\mathrm{GMH}$ yang tercatat 25 orang tetapi yang aktif 7 orang sukarelawan.

Senada dengan kondisi pembelajaran di SSC Surabaya, sarana dan prasarana GMH masih kurang memenuhi syarat untuk melaksanakan kegiatan belajar mengajar. Kegiatan pembelajaran yang telah dilakukan oleh GMH belum didukung oleh sarana dan prasarana yang lengkap, belum memiliki media pembelajaran layaknya seperti di sekolah formal. GMH belum memiliki tempat khusus untuk belajar, anak-anak belajar di salah satu rumah masyarakat sekitar Dolly. Anak marginal GMH juga mengalami kesulitan belajar matematika dan IPA. Pengajar GMH kebanyakan berasal dari latar belakang pendidikan yang berbeda-beda dan belum memiliki pengalaman mengajar dengan menggunakan media permainan Matematika dan IPA seperti halnya pengajar di SSC Surabaya. Para pengajar SSC dan GMH sangat membutuhkan pengetahuan dan keterampilan yang benar tentang cara membuat media permainan Matematika dan IPA yang sederhana. Bahwa media permainan Matematika dan IPA dapat dibuat dari bahan yang murah, aman, mudah diperoleh serta bersifat menyenangkan. Sehingga pengajar anak jalanan/marginal tidak terbebani biaya untuk membuat media permainan.

Pengajaran dengan menggunakan media permainan matematika dan IPA yang sederhana diharapkan akan membantu para pengajar SSC Surabaya dan GMH dalam menyampaikan materi pembelajaran Matematika dan IPA kepada anak jalanan dan anak terdampak penutupan lokalisasi Dolly. Anak-anak jalanan dan marginal dapat bermain sekaligus belajar atau dengan kata lain anak jalanan/marginal tidak merasa berat dalam belajar karena dikemas dalam permainan. Hal tersebut didukung oleh pernyataan Borich (2014) yang menyatakan bahwa pelaksanaan pembelajaran akan efektif jika didukung media yang berorientasi pada tujuan pembelajaran.
Berdasarkan analisis situasi di atas, menunjukkan bahwa komunitas SSC Surabaya dan GMH sangat membutuhkan uluran tangan dari para ahli pendidikan untuk ikut memberikan bantuan yang dibutuhkan oleh komunitas tersebut. Oleh karena itu, PKM lbM yang diusulkan untuk pengajar di SSC Surabaya dan GMH adalah "IbM Pengajar Anak Jalanan dan Marginal melalui Pelatihan Pembuatan Media permainan Matematika dan IPA".

\section{METODE PELAKSANAAN}

Berikut disajikan tahapan pelaksanaan kerja dalam PKM IbM ini.

Tahap Persiapan meliputi kegiatankegiatan observasi yang dilakukan di SSC Surabaya dan $\mathrm{GMH}$ dengan sasaran utama para pengajar anak jalanan dan marginal. Kemudian, menyusun dan menggandakan makalah pelatihan, menyiapkan alat dan bahan yang diperlukan untuk pelatihan bagi para peserta secara lengkap dan dalam jumlah yang memadai. Pada tahap persiapan juga disusun alat evaluasi pelatihan berupa angket respon peserta terhadap pelatihan pembuatan media permainan Matematika dan IPA yang Sederhana.

Tahap Pelaksanaan meliputi pelaksanaan pelatihan yang dilakukan di base camp Gerakan Melukis Harapan dan/atau SSC. Tahap pelaksanaan dilaksanakan 3 kegiatan, Kegiatan pertama Tim Pelaksana PKM IbM menyajikan cara Pembuatan Media Permainan Matematika, cara menulis aturan media permainan Matematika dan melakukan modeling mengajar Matematika dengan menggunakan media permainan yang telah dibuat. Kegiatan pertama diakhiri dengan penugasan kepada peserta untuk membuat media permainan matematika yang sederhana. Kegiatan kedua, dilaksanakan satu minggu setelah kegiatan pertama, para peserta pelatihan diharapkan dapat menunjukkan hasil pembuatan media permainan matematika dan aturan permainan. Kemudian, Tim IbM memberi pelatihan cara pembuatan media permainan IPA, cara menulis aturan permainan yang operasional dan modeling mengajar IPA dengan menggunakan media permainan yang telah dibuat. Kegiatan kedua diakhiri dengan penugasan kepada peserta untuk membuat media permainan IPA yang sederhana. Kegiatan ketiga, dilaksanakan satu minggu setelah kegiatan kedua, para peserta diharapkan dapat menunjukkan hasil 
pembuatan media permainan IPA dan aturan permainannya. Kemudian, peserta pelatihan melaksanakan simulasi mengajar anak jalanan dan marginal dengan menggunakan media permainan Matematika/IPA buatan sendiri.

Tahap Evaluasi yang dilaksanakan setelah selesai kegiatan pelatihan untuk mengetahui tanggapan peserta tentang pelatihan pembuatan media permainaan Matematika dan IPA yang sederhana. Secara skematis prosedur kerja pelaksanaan kegiatan IbM.

\section{HASIL DAN PEMBAHASAN}

Hasil judul pembuatan permainan MIPA sederhana yang telah dibuat oleh pengajar anak jalanan/marjinal sebagai proses pembelajaran disajikan dalam Tabel 1 sebagai berikut.

Tabel 1. Hasil Judul Permainan MIPA Sederhana yang Telah dibuat Pengajar Anak Jalanan/Marjinal

\begin{tabular}{cl}
\hline Kelompok & \multicolumn{1}{c}{ Judul Permainan } \\
\hline 1 & C3 (Catur Cerdas Cermat) \\
\hline 2 & Gobak Sodor \\
\hline 3 & KMH (Kalah Menang Hore) \\
\hline 4 & Ular Tangga (Makhluk Hidup dan Klasifikasi) \\
\hline 5 & Bank Karet \\
\hline 6 & Grepek Kampung \\
\hline 7 & Roda Berputar (Ciri Khusus Makhluk Hidup) \\
\hline
\end{tabular}

Bedasarkan hasil judul pembuatan permainan MIPA sederhana yang dihasilkan oleh para pengajar anak jalanan/marjinal sebagai proses pembelajaran (Tabel 1) memiliki singkat aturan permainan. Setiap permainan memiliki aturan tersendiri (Lampiran 1), aturan permainan tersebut dijabarkan sebagai berikut.

\section{Aturan Permainan IPA Sederhana}

1. C3 (Catur Cerdas Cermat)

a. Permainan ini dilakukan oleh dua kelompok dengan jumlah maksimal pemain adalah enam orang tiap timnya dan tiap pemain bergantian memainkan pion begiliran.

b. Seperti pada permainan atur biasa, tiap pemain akan mendapat pertanyaan (IPA) ketika melangkah dan berhasil memakan pion lawan.

c. Kemudian pemain akan mendapat kartu pertanyaan (IPA) sesuai dengan tempat pemain berhenti melangkah, jika mejawab dengan tepat maka akan mendapatkan poin +10 , jika gagal akan mendapatkan poin -10, akan tetapi tetap dapat memainkan pion lawan.

d. Pemenang ditentukan dari teraih poin tertinggi karena permainan ini menilai seberapa cerdas dan cermatnya pemain.

2. Gobak Sodor

a. Pemain minimal delapan orang yang dibagi menjadi dua tim (tim jaga dan tim pelari). Tim pelari harus berusaha melewati tantangan. Tim jaga harus bisa menggagalkan tim pelari untuk melewati tantangan.

b. Jika satu orang mati atau gugur maka dia keluar dari permainan dan mendapatkan pertanyaan. Jika satu orang gugur lagi maka keluar dan mendapatkan pertanyaan lagi. Mereka dapat bekerja sama dengan temannya yang gugur sebelumnya.

c. Jika yang gugur tadi dapat menjawab maka dia dapat bermain kembali.

d. Jika dari empat pemain menyisakan satu orang dianggap kalah.

e. Hukuman untuk penjaga setiap garis sama, dia harus keluar dari garis dan meneima pertanyaan.

f. Tim yang menang jika bisa kembali ketempat semula dengan lancar atau mendapat rumah.

3. $\mathrm{KMH}$ (Kalah Menang Hore)

a. Permainan dilakukan minimal 4 orang (1 menjadi wasit). Setelah itu membentuk lingkaran.

b. Kemudian bernyanyi (wajib lagu anak atau daerah). Per-anak menyanyikan 1 suku kata misalnya, ba-lon-ku-a-dali-ma.

c. Anak yang terakhi menyanyikan bait terakhir lagu akan mendapatkan pertanyaan, jika menang akan lanjut permainan, jika kalah maka keluar dalam lingkaran dab nedapatkan hukuman. 
d. Jika ada anak yang lupa lirik langsung mendapat pertanyaan juga.

e. Peserta yang kalah dan menang dipisahkan, peserta yang menang berhak memperi hukuman kepada peserta yang kalah.

4. Ular Tangga

a. Apabila keluar dadu angka 6 maka pemain akan mendapatkan satu pertanyaan lagi

b. Pada point (1) maka pemain akan mendapat dua pertanyaan, apabila pemain menjawab dengan benar kedua pertanyaan tersebut maka pemain boleh melanjutkan permainan. Apabila pemain hanya dapat menjawab satu pertanyaan saja maka pemain akan mengambil kartu kesempatan.

Kartu kesempatan tersebut terdiri dari enam pilihan :

1) Lanjut permainan

2) Berhenti satu putaran

3) Kembali ke permainan awal (start)

4) Maju tiga langkah

5) Mundur lima langkah

6) Maju lima langkah

c. Apabila pemain berhenti di ekor ular maka pemain akan mendapatkan pertanyaan lagi, apabila tidak dapat menjawab pertanyaan pemain akan turun ke bawah ular tetapi apabila dapat menjawab pertanyaan dengan benar lanjut ke permainan tetap pada kotak tersebut.

d. Apabila pemain berada pada tangga pemain tidak dapat langsung naik ke kotak selanjutnya sebelum menjawab pertanyaan yang diberikan. Apabila dapat menjawab pertanyaan maka pemain bisa naik keatas namun apabila tidak dapat menjawab pemain tetap pada kotak tersebut

e. Pemenang ditentukan apabila :

1) Salah satu pemain sudah mencapai finish terlebih dahulu

2) Ketika waktu telah berakhir akan dilihat dari angka yang paling besar dimana kotak terakhir pemain tersebut berada.

5. Bank Karet
a. 1 orang menjadi pegawai bank dan pengawas pemainan
b. Jumlah pemain tidak ada ketentuan
c. Pemain melakukan suit untuk menentukkan urutan main.

d. Jika lemparan masuk kedalam kotak maka mendapat pertanyaan.

e. Jika lemparan keluar dari kotak, gelang karet diambil pihak bank.

f. Jika berhasil menjawab maka mendapatkan poin atau jumlah karet sebanyak hasil kali dari kode soal yang didapat dan karet yang dilempar.

g. Jumlah karet yang dilempar menurut keinginan pemain.

h. Pihak bank menyerahkan gelang karet sejumlah 20 karet atau pemain.

i. Permainan berakhir ketika bank mengalami bangkrut (tidak ada dana)

6. Grepek Kampung

a. Materi IPA yang diajarkan yaitu perubahan zat meliputi zat cair, padat dan gas.

b. Membentuk kelompok 7-10 dan menentukan satu penjaga dengan cara hompimpa atau batu gunting kertas.

c. Cara bermain mula-mula menyusun menara "Perubahan Zat" lalu salah satu pemain selain penjaga melemparkan bola ake arah menara hingga runtuh.

d. Tugas penjaga yaitu menjaga menara agar tidak disusun, melemparkan bola ke pemain lain agar bertukar posisi.

e. Tugas pemain yaitu menyusun menara dan menghindari bola, menjawab pertanyaan kartu hukuman bila salah memasuki pos, dan menuju pos berikutnya sesuai instruksi pos sebelumnya.

f. Terdapat tiga pos yaitu, pos 1:zat cair, pos 2: zat padat, dan ps 3: zat gas. Tiap pos memegang dua tipe kartu. Pos 1 membeku dan menguap, pos 2 mencair dan mengembun, pos 3 menyublim atau mengkristal.

g. Tiap peserta yang masuk pos terbebas lembaran selama 10 detik, bila kartunya sesuai.

h. Bila tidak sesuai maka akan diberi kartu hukuman (dijawab 10 detik).

7. Roda Berputar
a. Materi yang diajarkan pada permainan roda berputar yaitu ciri khusus makhluk hidup.
b. Pemain memutar media roda sesuai urutan.


c. Setelah roda berhenti, pemain wajib menjawab ciri khusus hewan atau tumbuhan yang tertera dalam roda.

d. Pemain yang dapat menjawab dengan benar mendapat satu bintang.

e. Disepakati waktu yang dibutuhkan dalam sekali jawab.

f. Pemain yang tidak dapat menjawab dan melewati waktu yang ditentukan akan diteruskan ke pemain berikutnya. g. Pemain yang mendapatkan bintang terbanyak adalah juaranya.

Hasil penilaian pembuatan dan cara simulasi media MIPA sederhana yang dilakukan oleh pengajar anak jalanan/marjinal dinilai oleh pengamat dari kelompok pengajar anak jalanan/majinal lainnya dan dosen matematika Unesa yang ditinjau dari beberapa aspek penilaian akan disajikan dalam Tabel 2 dan Tabel 3 sebagai berikut.

Tabel 2. Rekapitulasi Data Penilaian Pembuatan Media MIPA Sederhana yang Telah Dibuat Oleh Peserta

\begin{tabular}{cccccccc}
\hline Aspek yang Dinilai & Kel. 1 & Kel. 2 & Kel. 3 & Kel. 4 & Kel. 5 & Kel. 6 & Kel. 7 \\
\hline Ide Pembuatan Media & 4 & 4 & 3 & 2 & 3 & 3 & 4 \\
\hline Alat dan Bahan & 4 & 3 & 4 & 4 & 4 & 4 & 4 \\
\hline $\begin{array}{c}\text { Prosedur Pembuatan } \\
\text { Media }\end{array}$ & 4 & 4 & 2 & 2 & 3 & 4 & 4 \\
\hline Kesesuaian Media & 4 & 4 & 4 & 4 & 4 & 4 & 4 \\
\hline Kebermanfaat Media & 3 & 3 & 3 & 4 & 2 & 4 & 4 \\
\hline Skor yang Diperoleh & 19 & 18 & 16 & 16 & 16 & 18 & 20 \\
\hline Nilai & 95 & 90 & 80 & 80 & 80 & 90 & 100 \\
\hline
\end{tabular}

Berdasakan Tabel 2 diatas diketahui nilai media MIPA sederhana yang dibuat oleh para pengajar anak jalanan/marjinal pada materi matematika dan IPA (IImu Pengetahuan Alam) memiliki nilai diatas rata-rata yaitu 70 100 dari beberapa aspek yang telah ditentukan (Lampiran 2). Media permainan MIPA sederhana yang dihasilkan yaitu 14 permainan, permainan tersebut merupakan beberapa permainan tradisional yang telah dimodifikasi oleh para pengajar anak jalanan/marjinal. Para pengajar anak jalanan/marjinal mengharapkan terdapat pelatihan lain selain pelatihan pembuatan media MIPA sederhana untuk meningkatkan kemampuan megajar anak jalanan/marjinal yaitu pelatihan tentang psikologis anak, penyusunan kurikulum, dan pelatihan outbound yang khususnya untuk anak-anak marjinal.

Tabel 3. Rekapitulasi Data Penilaian Simulasi Cara Mengajar Pengajar Anak Jalanan/Majinal dengan Media IPA Sederhana Buatan Sendiri

\begin{tabular}{cccccccc}
\hline Aspek yang Dinilai & Kel. 1 & Kel. 2 & Kel. 3 & Kel. 4 & Kel. 5 & Kel. 6 & Kel. 7 \\
\hline $\begin{array}{c}\text { Demonstrasi } \\
\text { Penggunaan Media }\end{array}$ & 4 & 4 & 2 & 3 & 4 & 4 & 4 \\
\hline Alokasi Waktu & 4 & 4 & 3 & 2 & 3 & 4 & 4 \\
\hline $\begin{array}{c}\text { Pembelajaran dengan } \\
\text { Permainan }\end{array}$ & 4 & 4 & 3 & 3 & 4 & 3 & 4 \\
\hline Kebahasaan & 4 & 4 & 4 & 4 & 4 & 4 & 4 \\
\hline Etika Simulasi & 4 & 4 & 3 & 4 & 4 & 3 & 4 \\
\hline Skor yang Diperoleh & $\mathbf{2 0}$ & $\mathbf{2 0}$ & $\mathbf{1 5}$ & $\mathbf{1 6}$ & $\mathbf{1 9}$ & $\mathbf{1 8}$ & $\mathbf{2 0}$ \\
\hline Nilai & $\mathbf{1 0 0}$ & $\mathbf{1 0 0}$ & $\mathbf{7 5}$ & $\mathbf{8 0}$ & $\mathbf{9 5}$ & $\mathbf{9 0}$ & $\mathbf{1 0 0}$ \\
\hline
\end{tabular}

Berdasarkan Tabel 3 diatas diketahui data nilai hasil simulasi cara mengajar pengajar anak jalanan/marjinan menggunakan media MIPA sederhana yang telah mereka buat memiliki nilai diatas rata-rata yaitu 70-100. Nilai yang diperoleh tersebut bedasarkan aspek yang telah ditentukan yaitu demonstrasi penggunaan media yang jelas mudah diikuti, operasional, dan sistematis, alokasi waktu cukup untuk mengaja materi dengan media sederhana, pembelajaran dengan permainan yang dilihat dai penyampaian aturan permainan, melibatkan siswa untuk aktif dalam pembelajaran, dan 
membimbing siswa berdiskusi untuk memahami materi. Selain itu dari segi kebahasaan dilihat dari penggunaan bahasa Indonesia sesuai EYD dan tidak menggunakan istilah yang menimbulkan makna ganda. Pada etika simulasi dilihat dari pandangan mata ke audience, memberi kesempatan audience untuk bertanya dan kepercayaan diri.

Kesan para pengajar anak jalanan/marjinal saat melakukan simulasi media permainan MIPA sederhana yaitu merasa menyenangkan karena dapat saling bertukar pendapat untuk meningkatkan kualitas proses pengajaran menggunakan media dan banyaknya inovasi dan kreasi yang ditemukan/dibuat oleh para pengajar anak jalanan/marjinal. Selain itu komentar untuk meningkatkan kegiatan pelatihan yaitu adanya tempat yang lebih luas, pelatihan dilakukan secara insentive dan banyaknya komunitas lain yang diundang.

Respons Pengajar Anak Jalanan/Marginal merupakan tanggapan mereka setelah mengikuti proses pelatihan pembuatan media permainan MIPA sederhana. Hasil rekapitulasi angket respons dapat dilihat dalam Tabel 4.

Tabel 4. Rekapitulasi Data Respons Pengajar Anak Jalanan/Marginal Terhadap Pelatihan Pembuatan Permainan IPA Sederhana

\begin{tabular}{lcc}
\hline \multicolumn{1}{c}{ Pertanyaan } & Respon & \\
\hline & Ya & Tidak \\
\hline Tempat Pelatihan & & \\
\hline Apakah tempat pelatihan nyaman? & 100 & 13 \\
\hline Apakah tempat pelatihan memiliki suasana yang kondusif? & 87 & \\
\hline Alokasi Waktu & 87 & 13 \\
\hline $\begin{array}{l}\text { Apakah alokasi waktu yang disediakan cukup untuk } \\
\text { memahami cara pembuatan permainan sederhana? }\end{array}$ & & 22 \\
\hline Apakah alokasi waktu efisien? & 78 & 13 \\
\hline Demonstrasi Pembuatan Media & & 0 \\
\hline $\begin{array}{l}\text { Apakah demonstrasi cara pembuatan media jelas dan mudah } \\
\text { dipahami? }\end{array}$ & 87 & 0 \\
\hline Apakah demonstrasi yang ditampilkan dapat Anda ikuti? & 100 & \\
\hline $\begin{array}{l}\text { Apakah demonstrasi yang ditampilkan menarik dan } \\
\text { menyenangkan? }\end{array}$ & 100 & 13 \\
\hline Demonstrasi Penulisan Aturan Permainan & & 13 \\
\hline Apakah demonstrasi penulisan jelas dan mudah diikuti? & 87 & \\
\hline Apakah demonstrasi sistematis? & 87 & \\
\hline Kebermanfaatan Pelatihan Pembuatan Media & & \\
\hline $\begin{array}{l}\text { Apakah kegiatan pelatihan pembuatan permainan menambah } \\
\text { wawasan Anda? }\end{array}$ & 100 & \\
\hline $\begin{array}{l}\text { Apakah Anda terinspirasi untuk membuat permainan } \\
\text { sederhana? }\end{array}$ & 96 & \\
\hline $\begin{array}{l}\text { Apakah Anda terinspirasi untuk menerapkan permainan } \\
\text { sederhana untuk mengajar anak jalanan/marginal? }\end{array}$ & & \\
\hline
\end{tabular}

Berdasarkan tabel hasil rekapitulasi angket respons menunjukkan bahwa para pengajar anak jalanan/marjinal menanggapi positif pembelajaran pada proses pelatihan pembuatan media permainan MIPA sederhana. Terdapat 12 pertanyaan yang dijawab oleh para pengajar anak jalanan/majinal, beberapa diantaranya mendapatkan 100\% tanggapan positif. Beberapa pernyataan yang mendapatkan $100 \%$ respons positif dari para pengajar adalah kegiatan pelatihan pembuatan media permainan MIPA sederhana dapat menambah wawasan bagi mereka. Selain itu terdapat beberapa komentar atau saran dari para pengajar yaitu, waktu lebih efisien, tempat untuk permainan yang memerlukan ruang lapang kurang dipenuhi, materi mengarah ke anak SD, dan lebih banyak media pembelajaran yang diberikan.

\section{Pembahasan}

Permainan edukatif adalah kegiatan yang mencakup tindakan tertentu yang di dalamnya terdapat peraturan-peraturan tertentu yang dilakukan oleh guru untuk tujuan kognitif emosional dan pendidikan. Permainan edukatif dirancang untuk 
membantu siswa dalam mempelajari keterampilan saat siswa bermain, juga membantu memperbaiki pemikiran, kreativitas dan meningkatkan kemampuan untuk mempertahankan informasi yang didapat siswa saat proses pembelajaran. (Becta, 2001; Najdi, 2010).

Ilmuwan percaya bahwa permainan edukatif dapat membuka pikiran siswa dan meningkatkan perasaan senang saat belajar, sehingga mengurangi beban informasi yang disampaikan oleh guru (Raya, 2001). Permainan edukatif juga mendukung dan memotivasi minat siswa untuk belajar (Alhela, 2010). Permainan pendidikan terbatas pada tiga bentuk; Permainan tradisional, game terkomputerisasi dan permainan teka-teki.

Hasil penelitian Samir Najdi dan Randa (2012) menunjukkan bahwa pentingnya permainan edukatif dalam mengembangkan sikap positif terhadap pembelajaran, dan dalam mengurangi ketegangan pada saat pembelajaran. Permainan edukatif terbukti mampu mengaktifkan kemampuan mental siswa, dan meningkatkan sikap positif mereka terhadap pembelajaran, yang memperdalam pemahaman topik yang dipelajari, terlebih lagi dapat mentransfer efek belajar ke topik lainnya. Dengan demikian, diyakini bahwa jika permainan edukatif direncanakan dengan baik, terorganisir dan diawasi, dapat berperan aktif dalam membangun sikap positif terhadap pembelajaran.

Menurut Naim Uzum (2012), melalui permainan edukatif, materi bisa jadi lebih menarik dan konsep baru bisa diajarkan lebih mudah, kesalahpahaman bisa dikoreksi dan informasi bisa dibuat lebih permanen. Anak mendapatkan pengalaman, mengembangkan taktik, mencari solusi, dan membuat banyak keputusan saat bermain. Dengan cara ini, semua keterampilan, nilai, dan tujuan target dapat dicapai melalui permainan.

Permainan dianggap sebagai cara yang tepat untuk memusatkan pelajar, sehingga memungkinkan untuk belajar dengan cara yang berarti, untuk menekankan pemecahan masalah, dan membuat pembelajaran sebagai proses pemahaman yang aktif (Prensky, 2001). Permainan dapat memberi motivasi kepada siswa untuk terlibat aktif dalam pembelajaran tersebut (Malone dan Lepper, 1987). Terdapat tujuh faktor yang mencakup faktor individu dan interpersonal telah dipostulasikan untuk meningkatkan motivasi intrinsik. Faktor individu adalah tantangan, rasa ingin tahu, kontrol, fantasi, persaingan, kerja sama dan pengakuan.
Faktor-faktor tesebut dapat dipicu dengan menggunakan permainan (Kordaki, 2014; Prensky, 2001). Permainan juga memberikan konteks yang berarti bagi siswa yang dilihat dari hasilnya, menang atau kalah (Ainley, 1990). Selain itu, permainan tidak hanya menyediakan sumber motivasi yang kuat untuk keterlibatan siswa dalam belajar, tetapi juga dapat mendorong perkembangan sosial, emosional dan kognitif siswa (Kordaki, 2014).

Interaksi sosial merupakan ciri khas permainan yang didasarkan pada teori konstruktivis. Permainan tidak hanya memiliki potensi untuk menciptakan konteks untuk perolehan pengetahuan tetapi juga untuk membentuk sebuah komunitas atau keadaan bersosialisasi (Shaffer, 2006). Berbagi pendapat dengan kelompok cenderung memotivasi dan memfasilitasi pembelajaran sebagai proses alami, di mana siswa memperoleh pengetahuan secara bertahap sejauh ia mampu bekerja dengan kelompok.

Baru-baru ini, terdapat subdomain spesifik dari permainan edukatif STEM (Science, Technology, Engineering, and Mathematics), telah mendapat banyak perhatian penelitian. Biasanya, studi evaluatif ini menggunakan ruang kelas sebagai lingkungan penelitian yang terkendali. Misalnya, Chang et al (2015) mempelajari keterlibatan siswa dalam reaksi terhadap aplikasi pecahan di iPod Touch, memberikan perhatian khusus pada siswa. Pareto dan Kolega (2011) menyelidiki pemahaman, sikap, dan self-efficacy siswa setelah bermain Game Aritmatika Agen Guru, sementara Katmada et al (2014) berfokus pada kegunaan permainan Tupai Vulkanik. Castellar (2015) mempelajari kemampuan kognitif dan kinerja matematika dalam sebuah studi jangka panjang di mana siswa memainkan permainan matematika komersial Monkey Tales di rumah.

Sebagian besar penelitian dilakukan dalam pengaturan yang terkontrol, dengan sesi permainan yang diatur dalam konteks pembelajaran formal, yang diawasi oleh peneliti atau guru dan ruang kelas yang telah disetting (Hamlen, 2011). Namun, permainan edukatif semakin banyak digunakan di luar kelas, dengan setting informal. Penggunaan permainan edukatif di luar kelas memerlukan penelitian tambahan mengenai pengaruh lingkungan rumah yang kurang terkontrol terhadap persepsi dan pengalaman dengan permainan edukatif.

Sampai saat ini, hanya sedikit penelitian yang mempelajari secara rinci bagaimana anak bermain game matematika pendidikan di 
rumah. Konteks rumah, karena kurang terstruktur dan diawasi secara kaku daripada konteks kelas formal, dapat diharapkan memiliki pengaruh pada bagaimana permainan pendidikan dirasakan dan disesuaikan. Di rumah, orang tua tidak harus menentukan peraturan yang kaku, pedagogi yang direncanakan atau kerangka waktu tertentu untuk bermain game pendidikan (Nolan dan Mcbride, 2014).

\section{SIMPULAN DAN SARAN}

Kegiatan ini meliputi empat tahap utama. Tahap pertama, adalah mendemonstrasikan cara membuat media permainan IPA yang sederhana. Tahap kedua, mendemonstrasikan cara menulis aturan permainan dengan kalimat yang mudah diikuti atau operasional. Tahap ketiga, melakukan modeling cara mengajar dengan menggunakan media permainan IPA. Pada setiap langkah diikuti penugasan secara kelompok. Tahap keempat, setiap kelompok pengajar diminta mendemonstrasikan permainan IPA sederhana buatan sendiri. Hasil kegiatan menunjukkan dari 8 kelompok pengajar anak jalanan dan marginal berhasil membuat 7 permainan IPA sederhana dengan baik dan melakukan simulasi permainan buatan sendiri.

\section{DAFTAR PUSTAKA}

Ainley, J. 1990. Playing games and learning mathematics. In L. P. Steffe \& T. Wood (Eds.), Transforming children's mathematics education: International perspectives. Hillsdale, NJ: Erlbaum, pp.84-91.

Alhela, M. 2010. Educational Games and Their production techniques psychological, educational and practical. (5th ed), Dar march, Amman, Jordan.

Castellar, E.N, A. All, L. de Marez, J. Van Looy. 2015. Cognitive abilities, digital games and arithmetic performance enhancement: a study comparing the effects of a math game and paper exercises, Comput. Educ. 85 (2015) 123-133.

Chang, M., M.A. Evans, S. Kim, A. Norton, K. Deater-Deckard, Y. Samur. 2015. The effects of an educational video game on mathematical engagement, Educ. Inf. Technol. 21 (5), pp 1283-1297.
Hamlen, K.R. Children's choices and strategies in video games, Comput. Hum. Behav. 27 (2011) 532-539.

Katmada, A., A. Mavridis, T. Tsiatsos. 2014. Implementing a game for supporting learning in mathematics, Electron. J. eLearn. 12 (3) (2014) 230-242.

Kordaki, M. 2014. A Constructivist, Modeling Methodology for the Design of Educational Card Games. Social and Behavioral Sciences, 191 (2015) 26 30.

Malone, T. W., \& Lepper, M. R. 1987. Making learning fun: A taxonomic model of intrinsic motivations for learning. In R. E. Snow \& M. J. Farr (Eds.), Aptitude, learning, and instruction: III. Cognitive and affective process analysis (pp. 223-253). Hillsdale, NJ: Erlbaum.

Najdi, R. 2010. Importance of Math Educational Games on the Attitudes of Students towards Learning Math from Teachers and Learning Perspectives, First Educational Conference: School Education in Palestine in response to the present and the future.

Nolan, J, M. McBride. 2014. beyond gamification: reconceptualizing gamebased learning in early childhood environments, Inform. Commun. Soc. 17 (5) (2014) 594-608.

Pareto, L, T. Arvemo, Y. Dahl, M. Haake, A. Gulz. 2011. A teachable-agent arithmetic game's effects on mathematics understanding, attitude and self-efficacy, in: G. Biswas, S. Bull, J. Kay, A. Mitrovic (Eds.), Artificial Intelligence in Education, Springer, Berlin Heidelberg, pp. 247-255.

Riya, Abu M. 2001. The Impact of Using Computerized Games in the Sixth Grade Students in Acquiring the Four Arithmetic Algorithms. Studies of Educational Sciences. 28, (pp :164 176).

Shaffer, D.W. 2006. Epistemic frames for epistemic games. Computers \& Education, 46(3), $223 \mathrm{e} 234$.

Uzun, Naim. 2012. A sample of active learning application in science education: The thema "cell" with educational games. Procedia - Social and Behavioral Sciences 46 ( 2012 ) $2932-2936$ 